\title{
Article \\ Effect of Berberine on Cardiovascular Disease Risk Factors: A Mechanistic Randomized Controlled Trial
}

\author{
Jie V. Zhao ${ }^{1, *}$, Wai-Fung Yeung ${ }^{1}$, Yap-Hang Chan ${ }^{2}$, Dana Vackova ${ }^{1}{ }^{\mathbb{D}}$, June Y. Y. Leung ${ }^{1}$, Dennis K. M. Ip ${ }^{1}$, \\ Jiaxi Zhao ${ }^{3}$, Wai-Kwan Ho ${ }^{4}$, Hung-Fat Tse ${ }^{2,5}$ and Catherine Mary Schooling 1,6
}

check for updates

Citation: Zhao, J.V.; Yeung, W.-F.; Chan, Y.-H.; Vackova, D.; Leung, J.Y.Y.; Ip, D.K.M.; Zhao, J.; Ho, W.-K.; Tse, H.-F.; Schooling, C.M. Effect of Berberine on Cardiovascular Disease Risk Factors: A Mechanistic Randomized Controlled Trial. Nutrients 2021, 13, 2550. https:// doi.org/10.3390/nu13082550

Received: 12 June 2021

Accepted: 12 July 2021

Published: 26 July 2021

Publisher's Note: MDPI stays neutral with regard to jurisdictional claims in published maps and institutional affiliations.

Copyright: (c) 2021 by the authors. Licensee MDPI, Basel, Switzerland. This article is an open access article distributed under the terms and conditions of the Creative Commons Attribution (CC BY) license (https:// creativecommons.org/licenses/by/ $4.0 /)$.
1 School of Public Health, Li Ka Shing Faculty of Medicine, The University of Hong Kong, Hong Kong, China; owen22@hku.hk (W.-F.Y.); vackova@hku.hk (D.V.); leungjy@hku.hk (J.Y.Y.L.); dkmip@hku.hk (D.K.M.I.); cms1@hku.hk (C.M.S.)

2 Division of Cardiology, Queen Mary Hospital, Hong Kong, China; cyh472@ha.org.hk (Y.-H.C.); hftse@hkucc.hku.hk (H.-F.T.)

3 Department of Pharmacology and Pharmacy, The University of Hong Kong, Hong Kong, China; jxzhao@hku.hk

4 Department of Chinese Medicine, Pok Oi Hospital, Hong Kong, China; cmscp1@pokoi.org.hk

5 Department of Medicine, Li Ka Shing Faculty of Medicine, The University of Hong Kong, Hong Kong, China

6 School of Public Health and Health Policy, City University of New York, New York, NY 10027, USA

* Correspondence: janezhao@hku.hk

\begin{abstract}
Cardiovascular disease (CVD) is a major contributor to the global burden of disease. Berberine, a long-standing, widely used, traditional Chinese medicine, is thought to have beneficial effects on CVD risk factors and in women with polycystic ovary syndrome. The mechanisms and effects, specifically in men, possibly via testosterone, have not been examined previously. To assess the effect of berberine on CVD risk factors and any potential pathway via testosterone in men, we conducted a randomized, double-blind, placebo-controlled, parallel trial in Hong Kong. In total, 84 eligible Chinese men with hyperlipidemia were randomized to berberine (500 mg orally, twice a day) or placebo for 12 weeks. CVD risk factors (lipids, thromboxane A2, blood pressure, body mass index and waist-hip ratio) and testosterone were assessed at baseline, and 8 and 12 weeks after intervention. We compared changes in CVD risk factors and testosterone after 12 weeks of intervention using analysis of variance, and after 8 and 12 weeks using generalized estimating equations (GEE). Of the 84 men randomized, 80 men completed the trial. Men randomized to berberine had larger reductions in total cholesterol $(-0.39 \mathrm{mmol} / \mathrm{L}, 95 \%$ confidence interval (CI) -0.70 to -0.08$)$ and high-density lipoprotein cholesterol $(-0.07 \mathrm{mmol} / \mathrm{L}, 95 \% \mathrm{CI}-0.13$ to -0.01$)$ after 12 weeks. Considering changes after 8 and 12 weeks together, berberine lowered total cholesterol and possibly low-density lipoprotein-cholesterol (LDL-c), and possibly increased testosterone. Changes in triglycerides, thromboxane A2, blood pressure, body mass index and waist-hip ratio after the intervention did not differ between the berberine and placebo groups. No serious adverse event was reported. Berberine is a promising treatment for lowering cholesterol. Berberine did not lower testosterone but instead may increase testosterone in men, suggesting sex-specific effects of berberine. Exploring other pathways and assessing sex differences would be worthwhile, with relevance to drug repositioning and healthcare.
\end{abstract}

Keywords: berberine; randomized controlled trial; testosterone

\section{Introduction}

Cardiovascular disease (CVD) is a major contributor to the global burden of morbidity and mortality, with higher incidence and mortality rates in men than in women [1,2], and a corresponding need for, possibly sex-specific, innovations in prevention and treatment. Recently, development of new therapeutics for CVD prevention and treatment focusing on addressing lipid and inflammatory pathways has encountered repeated expensive failures, which has discouraged investment [3]. 
Berberine, an isoquinoline plant alkaloid [4], is widely used in traditional Chinese and Ayurvedic medicine [5]. Berberine is thought to have a range of beneficial effects on the cardiovascular system, including anti-lipidemic $[5,6]$ and anti-inflammatory properties [5], with good safety [5-8]. Berberine is highly concentrated in the roots, rhizomes and stem bark of several plants, such as Coptis (Huanglian), Rhizoma coptidis and Hydrastis canadensis (goldenseal) [9]. Berberine is extracted from Coptis (Huanglian) and Phellodendron Chinese (Huangbai), to make into compound berberine tablets, currently used in clinical practice for digestive diseases [8]. Berberine is also widely used as a nutrient supplement in the US.

Although berberine has been in use for thousands of years, the mechanisms by which berberine exerts its effects are unclear. Several pathways have been proposed. One possibility is activation of the adenosine monophosphate-activated protein kinase (AMPK) pathway that coordinates energy balance and lipid synthesis $[10,11]$. AMPK is also targeted by an established treatment for diabetes, i.e., metformin. Another possibility is inhibition of the aldo-keto reductase family 1 member C3 (AKR1C3), that regulates steroid hormone action, such as estrone to $17 \beta$-estradiol or androstendione to testosterone conversion [12]. Sex hormones have long been thought relevant to CVD because of the difference in incidence by sex. Estrogen has been extensively investigated, but is no longer thought to be highly relevant [13], while the role of androgens is being more extensively investigated [14] for empirical and theoretical reasons $[15,16]$. A Mendelian randomization study, to minimize confounding, in Chinese men suggested that higher testosterone may be associated with more unfavorable cardiac function [17] and unhealthier lipids, i.e., including lower high-density lipoprotein cholesterol (HDL-c) [18]. A meta-analysis of RCTs suggested that testosterone lowers HDL-c [19], and raises the risk of thrombosis [20], possibly by inducing platelet aggregation via thromboxane A2 [21,22]. Berberine has been reported to lower total testosterone in women [23], whilst effects on testosterone in men have not been examined.

Systematic reviews and meta-analyses of clinical trials have shown a lipid-lowering effect of berberine in people with hyperlipidemia with or without coronary heart disease or diabetes $[5,6,24]$, as well as potential benefits on blood pressure and adiposity $[8,25,26]$, with no serious adverse events $[5,6,8,27]$. However, these trials vary in quality and design, making meta-analyses difficult to interpret [6]. Publication bias is also possible [24]. To address these gaps and the case for translation, we conducted a mechanistic, parallel, randomized, double-blind, placebo-controlled trial in Chinese men with hyperlipidemia to examine the effects of berberine on a set of well-established CVD risk factors, specifically, lipids, thromboxane A2, systolic and diastolic blood pressure and adiposity. We also assessed the hypothesis that berberine lowers testosterone, and if so, whether it mediates the effect of berberine on CVD risk factors. We limited the study to men because men have a substantially higher rate of CVD than women $[2,28]$.

\section{Materials and Methods}

\subsection{Study Design}

This is a randomized, parallel, double-blind, placebo-controlled trial conducted in Hong Kong. This trial was registered in ClinicalTrials.gov of the United States (NCT03770325) and conducted according to a pre-specified protocol. The trial was conducted following the requirement of International Council for Harmonisation (ICH) Good Clinical Practice (GCP) standards, and reported according to the Consolidated Standards of Reporting Trials (CONSORT) guidelines.

\subsection{Subjects}

We recruited volunteers from staff and/or their families at the University of Hong Kong and from an out-patient clinic in the Department of Medicine, Queen Mary Hospital, with the sample size calculated based on previous studies (as shown in the Supplementary Methods [29,30]), according to the following inclusion criteria: (1) age 20 to 65 years, (2) 
of Chinese ethnicity, (3) with hyperlipidemia, defined following the National Cholesterol Education Program Adult Treatment Panel III [31] as triglycerides greater than $150 \mathrm{mg} / \mathrm{dl}$ $(1.70 \mathrm{mmol} / \mathrm{L})$, total cholesterol greater than $200 \mathrm{mg} / \mathrm{dl}(5.16 \mathrm{mmol} / \mathrm{L})$, and /or LDL-c greater than $100 \mathrm{mg} / \mathrm{dl}$ (2.58 mmol/L), (4) willing to make return visits, (5) not having received hormone replacement therapy, such as testosterone replacement therapy, in the past 12 months, (6) not currently taking berberine or nutraceuticals that contain berberine, (7) free of any congenital conditions, including familial hypercholesterolemia, (8) free of any infectious diseases, e.g., seasonal influenza, (9) with no history of chronic diseases including ischemic heart disease, myocardial infarction, stroke, diabetes, cancer and liver or renal dysfunction. The participants were given an assessment report and a supermarket voucher, worth $300 \mathrm{HKD}$ ( 38 US dollars), at the end of the study as an incentive.

\subsection{Ethical Considerations}

Ethical approval was obtained from the Institutional Review Board of the University of Hong Kong/Hospital Authority Hong Kong West Cluster (UW18-037). The trial would have been discontinued immediately after receiving notification of any serious clinical adverse event. All participants were provided full information about the trial, informed that participation was voluntary and that they could decline further participation at any time without penalty, and signed a consent form before participation, including consent for use of left-over samples for future research.

\subsection{Intervention and Study Outcomes}

Intervention: purified berberine tablets (500 $\mathrm{mg}$ orally twice a day), which have been shown to be safe and effective in lipid-lowering in previous trials [7,32], or placebo tablets, prepared with the same appearance, were administered for 12 weeks.

Primary outcomes: lipids (total cholesterol, low-density lipoprotein cholesterol (LDL-c), triglycerides, HDL-c, thromboxane A2, systolic and diastolic blood pressure, and serum testosterone).

Secondary outcomes: Body mass index (BMI) and waist-hip ratio (WHR).

\subsection{Randomization, Allocation Concealment and Blinding}

Computer-generated random numbers were used to randomize half the participants to berberine, and half to placebo. A statistician prepared identical, opaque envelopes, with a unique identifier comprised of the random number on the cover of each envelope, and prepared berberine or placebo according to the corresponding allocation code. The allocation codes were only known to the statistician who prepared them. Participants and all others involved in the study, including those conducting the follow-up and performing the laboratory tests, did not know the link between the unique identifier and the allocation code.

\subsection{Data Collection}

Participants who agreed to participate were assessed for eligibility at the first visit, according to the inclusion criteria. At the second visit, eligible participants provided informed consent, and were provided a copy of the consent and information on how to contact the study staff at all times. Participants were then randomized to the berberine or placebo group. Participants completed a questionnaire including medical history, smoking status, alcohol use, physical activity, use of lipid-lowering therapies and socio-demographics. Fasting blood $(20 \mathrm{~mL})$ was taken for biochemical assessment and the remaining was stored at $-80{ }^{\circ} \mathrm{C}$. Weight, height, WHR and blood pressure were measured. An automated oscillometric device was used for blood pressure measurement.

When the participants returned at 8 weeks (third visit) and 12 weeks (fourth visit) post-intervention, the same assessments were performed using the same procedures. Participants were asked whether any discomfort had occurred during the study. After completion of all the visits, participants were given an assessment report and the supermarket voucher. 


\subsection{Biochemical Assessment}

Blood samples were tested using a Hitachi automated analyzer for lipids, an enzymelinked immunosorbent assay (ELISA) for thromboxane A2 and a competitive immunoassay for serum testosterone.

\subsection{Statistical Analysis}

Intention to treat analysis according to the randomization is the principal of analysis, where applicable. In the situation of loss to follow-up, as recommended by the Cochrane Handbook [33], an available case analysis was used. We calculated changes after 8 and 12 weeks and assessed differences between the berberine and placebo groups using analysis of variance. We assessed whether changes in serum testosterone differed between groups after 8 or 12 weeks, and if so, we assessed mediation by testosterone. We also used a generalized estimating equation (GEE) model with an exchangeable correlation matrix [34]. The GEE model uses the quasi-likelihood estimation, and is being increasingly applied to analyze longitudinal and other correlated data [35]. Given that we had repeated posttreatment measurements, we used the GEE model to make the best use of all the data. All statistical analyses were conducted using $R$ version 4.0.1 ( $R$ Foundation for Statistical Computing, Vienna, Austria).

\section{Results}

Using recruitment by advertisements, email and distribution of leaflets, 135 men showed interest in the trial. Of these 135 men interested in the trial, we included 84 eligible men, with 42 in the berberine group and 42 in the placebo group (Figure 1). Two men in each group withdrew due to not feeling well (Supplementary Table S1) and for other personal reasons, leaving 40 men in each group for analysis. Characteristics were similar in both groups (Table 1).

Table 1. Baseline characteristics of the participants in the berberine and placebo groups.

\begin{tabular}{|c|c|c|}
\hline \multirow{2}{*}{ Characteristics } & \multicolumn{2}{|c|}{ Number (Percentage) or Mean (SD) * } \\
\hline & Berberine Group & Placebo Group \\
\hline \multicolumn{3}{|l|}{ Place of birth } \\
\hline - Hong Kong & $36(90 \%)$ & $33(82.5 \%)$ \\
\hline - Macau & $0(0 \%)$ & $2(5 \%)$ \\
\hline - Mainland China & $4(10 \%)$ & $5(12.5 \%)$ \\
\hline \multicolumn{3}{|l|}{ Education level } \\
\hline - Primary school & $6(15.0 \%)$ & $7(17.5 \%)$ \\
\hline - High school & $25(62.5 \%)$ & $20(50 \%)$ \\
\hline - University and above & $9(22.5 \%)$ & $13(32.5 \%)$ \\
\hline \multicolumn{3}{|l|}{ Smoking status } \\
\hline - Non-smoker & $24(60 \%)$ & $30(75 \%)$ \\
\hline - Ex-smoker & $12(30 \%)$ & $5(12.5 \%)$ \\
\hline - Current smoker & $4(10 \%)$ & $5(12.5 \%)$ \\
\hline \multicolumn{3}{|l|}{ Alcohol drinking } \\
\hline - Never & $6(15.0 \%)$ & $8(20 \%)$ \\
\hline - Ex-drinker & $10(25.0 \%)$ & $8(20 \%)$ \\
\hline - Less than 1 day per week & $15(37.5 \%)$ & $15(37.5 \%)$ \\
\hline -1-2 days per week & $3(7.5 \%)$ & $7(17.5 \%)$ \\
\hline - 3-7 days per week & $6(15 \%)$ & $2(5 \%)$ \\
\hline Age (year) & $49.5(11.1)$ & $44.8(13.5)$ \\
\hline \multicolumn{3}{|l|}{ Physical activity } \\
\hline $\begin{array}{c}\text { Time of doing vigorous physical activity per } \\
\text { day (minutes) }\end{array}$ & $85.0(43.7)$ & $71.0(60.9)$ \\
\hline $\begin{array}{l}\text { Time of doing moderate physical activity per } \\
\text { day (minutes) }\end{array}$ & $69.6(51.0)$ & $76.8(83.9)$ \\
\hline $\begin{array}{l}\text { Time of doing light physical activity per day } \\
\text { (minutes) }\end{array}$ & $67.3(61.2)$ & $60.0(59.9)$ \\
\hline
\end{tabular}

SD, standard deviation. * Number (percentage) was used for categorical variables, mean (SD) was used for continuous variables. 


\section{CONSORT}

TRANSPARENT REPORTING of TRIALS

\section{CONSORT 2010 Flow Diagram}

\section{Enrolliment}

$$
\text { Assessed for eligibility }(n=135)
$$

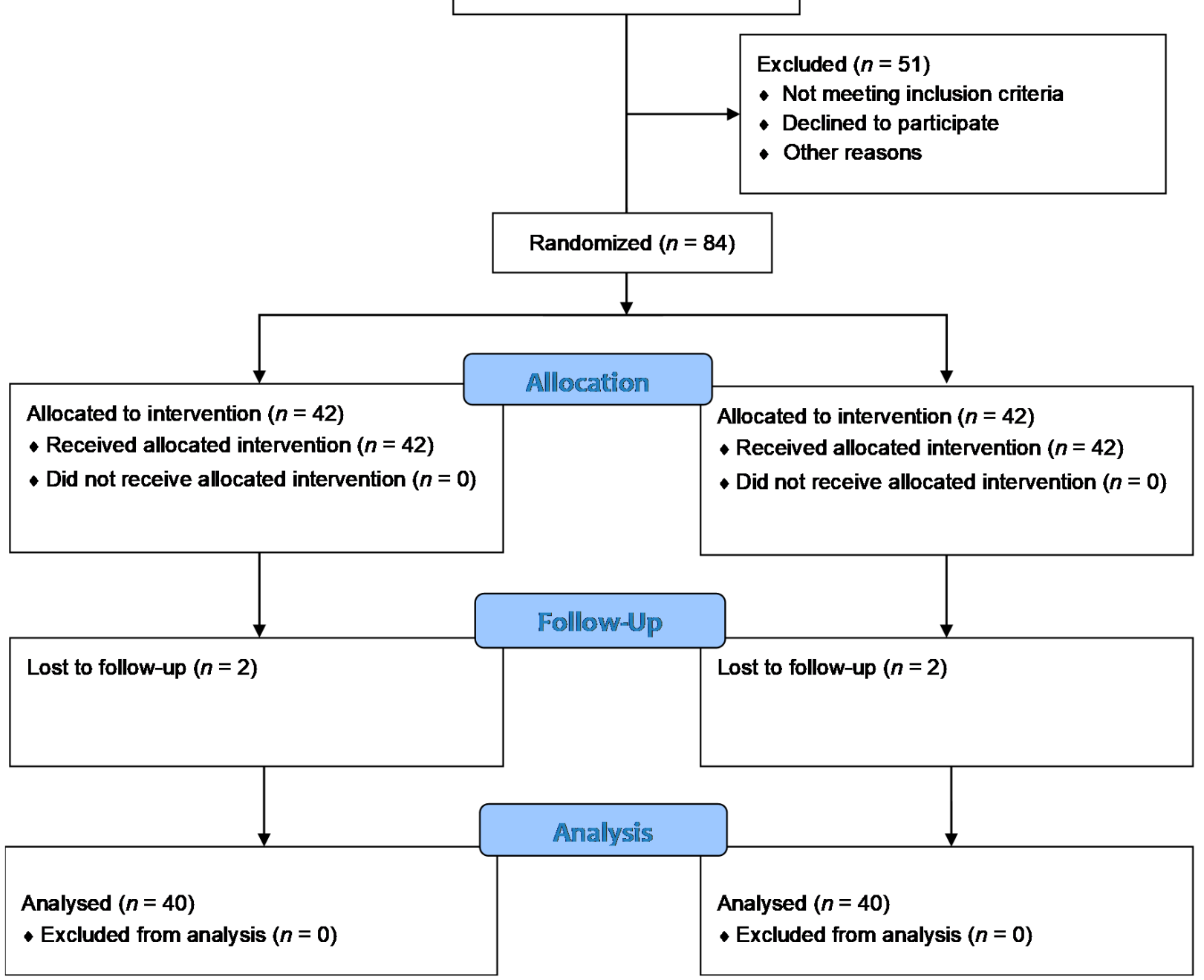

Figure 1. Flow chart.

After 12 weeks of intervention, men taking berberine had a larger reduction in total cholesterol and HDL-c than those taking placebo (Table 2). Similar effects on total cholesterol were evident after 8 weeks of intervention (Table 3). Consistent with previous studies [5,27], berberine was safe with no serious adverse events (Supplementary Table S1). 
Table 2. Baseline and 12-week post-treatment outcomes in the berberine and placebo groups.

\begin{tabular}{|c|c|c|c|c|c|c|c|}
\hline \multirow{2}{*}{ Outcomes } & \multicolumn{2}{|c|}{ Berberine (Mean (SD)) } & \multicolumn{2}{|c|}{ Placebo (Mean (SD)) } & \multicolumn{3}{|c|}{$\begin{array}{l}\text { Comparing the Changes in Two Groups } \\
\text { (Change (Berberine)-Change (Placebo)) }\end{array}$} \\
\hline & Baseline & $\begin{array}{l}\text { 12-Week } \\
\text { Treatment }\end{array}$ & Baseline & $\begin{array}{l}\text { 12-Week } \\
\text { Treatment }\end{array}$ & beta & $95 \%$ CI & $p$ \\
\hline $\begin{array}{l}\text { Total cholesterol } \\
(\mathrm{mmol} / \mathrm{L})\end{array}$ & $5.4(0.9)$ & $4.9(1.0)$ & $5.5(1.1)$ & $5.4(1.0)$ & -0.39 & $\begin{array}{l}-0.70 \\
-0.08\end{array}$ & 0.02 \\
\hline $\begin{array}{l}\text { LDL-cholesterol } \\
(\mathrm{mmol} / \mathrm{L})\end{array}$ & $3.3(0.8)$ & $3.0(0.8)$ & $3.5(1.0)$ & $3.4(0.9)$ & -0.21 & $-0.50,0.08$ & 0.15 \\
\hline $\begin{array}{l}\text { Triglycerides } \\
(\mathrm{mmol} / \mathrm{L})\end{array}$ & $1.9(0.8)$ & $1.6(0.9)$ & $1.8(1.3)$ & $1.6(1.0)$ & -0.08 & $-0.37,0.21$ & 0.60 \\
\hline $\begin{array}{l}\text { HDL-cholesterol } \\
(\mathrm{mmol} / \mathrm{L})\end{array}$ & $1.17(0.3)$ & $1.13(0.3)$ & $1.21(0.4)$ & $1.24(0.4)$ & -0.07 & $\begin{array}{l}-0.13 \\
-0.01\end{array}$ & 0.03 \\
\hline SBP (mmHg) & $131(16.8)$ & $130(17.8)$ & $125(12.7)$ & 125 (11.6) & -1.53 & $-7.47,4.41$ & 0.62 \\
\hline $\mathrm{DBP}(\mathrm{mmHg})$ & $88.3(13.8)$ & $86.6(13.0)$ & $82.1(10.8)$ & $81.0(9.0)$ & -0.58 & $-4.52,3.36$ & 0.78 \\
\hline BMI & $26.1(3.8)$ & $26.0(4.0)$ & $26.3(3.7)$ & $26.5(3.7)$ & -0.27 & $-0.74,0.20$ & 0.26 \\
\hline WHR & $0.93(0.06)$ & $0.92(0.06)$ & $0.91(0.05)$ & $0.91(0.06)$ & -0.01 & $-0.03,0.01$ & 0.26 \\
\hline $\begin{array}{l}\text { Thromboxane A2 } \\
\text { (pg/mL) }\end{array}$ & $188(109)$ & $255(162)$ & $198(107)$ & $243(138)$ & 21.46 & $-21.7,64.6$ & 0.33 \\
\hline $\begin{array}{l}\text { Testosterone } \\
(\mathrm{nmol} / \mathrm{L})\end{array}$ & $14.3(4.5)$ & $15.0(4.6)$ & $15.8(5.8)$ & $15.1(5.4)$ & 1.43 & $-0.10,2.96$ & 0.07 \\
\hline
\end{tabular}

Abbreviations: LDL: Low Density Lipoprotein; HDL: High Density Lipoprotein; SBP: systolic blood pressure; DBP: diastolic blood pressure; BMI: Body Mass Index; WHR: waist-hip ratio.

Table 3. Baseline and 8-week post-treatment outcomes in the berberine and placebo groups.

\begin{tabular}{|c|c|c|c|c|c|c|c|}
\hline \multirow{2}{*}{ Outcomes } & \multicolumn{2}{|c|}{ Berberine (Mean (SD)) } & \multicolumn{2}{|c|}{ Placebo (Mean (SD)) } & \multicolumn{3}{|c|}{$\begin{array}{l}\text { Comparing the Changes in Two Groups } \\
\text { (Change (Berberine)-Change (Placebo)) }\end{array}$} \\
\hline & Baseline & $\begin{array}{l}\text { 8-Week } \\
\text { Treatment }\end{array}$ & Baseline & $\begin{array}{c}\text { 8-Week } \\
\text { Treatment }\end{array}$ & beta & $95 \% \mathrm{CI}$ & $p$ \\
\hline $\begin{array}{l}\text { Total cholesterol } \\
(\mathrm{mmol} / \mathrm{L})\end{array}$ & $5.4(0.9)$ & $4.6(0.9)$ & $5.5(1.1)$ & $5.1(1.2)$ & -0.39 & $-0.72,-0.06$ & 0.03 \\
\hline $\begin{array}{l}\text { LDL-cholesterol } \\
(\mathrm{mmol} / \mathrm{L})\end{array}$ & $3.3(0.8)$ & $2.9(0.8)$ & $3.5(1.0)$ & $3.3(0.9)$ & -0.25 & $-0.54,0.04$ & 0.11 \\
\hline $\begin{array}{l}\text { Triglycerides } \\
(\mathrm{mmol} / \mathrm{L})\end{array}$ & $1.9(0.8)$ & $1.5(0.8)$ & $1.8(1.3)$ & $1.9(2.2)$ & -0.53 & $-1.22,0.16$ & 0.13 \\
\hline $\begin{array}{l}\text { HDL-cholesterol } \\
(\mathrm{mmol} / \mathrm{L})\end{array}$ & $1.17(0.3)$ & $1.07(0.3)$ & $1.21(0.4)$ & $1.10(0.5)$ & 0.01 & $-0.09,0.11$ & 0.86 \\
\hline SBP (mmHg) & $131(16.8)$ & $129(21.8)$ & $125(12.7)$ & $124(10.6)$ & -0.30 & $-5.32,4.72$ & 0.91 \\
\hline $\mathrm{DBP}(\mathrm{mmHg})$ & $88.3(13.8)$ & $86.7(16.7)$ & $82.1(10.8)$ & $80.5(12.3)$ & -0.05 & $-4.83,4.73$ & 0.98 \\
\hline BMI & $26.1(3.8)$ & $25.5(5.3)$ & $26.3(3.7)$ & $26.2(3.6)$ & -0.51 & $-1.63,0.61$ & 0.38 \\
\hline WHR & $0.93(0.06)$ & $0.93(0.06)$ & $0.91(0.05)$ & $0.91(0.05)$ & -0.001 & $-0.02,0.02$ & 0.95 \\
\hline $\begin{array}{l}\text { Thromboxane A2 } \\
\text { (pg/mL) }\end{array}$ & $188(109)$ & $214(104)$ & $198(107)$ & $228(145)$ & -4.5 & $-51.1,42.1$ & 0.85 \\
\hline $\begin{array}{l}\text { Testosterone } \\
(\mathrm{nmol} / \mathrm{L})\end{array}$ & $14.3(4.5)$ & $14.7(4.7)$ & $15.8(5.8)$ & $15.0(5.2)$ & 1.19 & $-0.18,2.56$ & 0.09 \\
\hline
\end{tabular}

Using a GEE model to include information at both timepoints (8 and 12 weeks) obtained a similar estimate for total cholesterol and no association for HDL-cholesterol (Table 4). However, the reduction in LDL-c and the increase in testosterone were statistically significant (Table 4). No differences in triglycerides, thromboxane A2, blood pressure, BMI or WHR were evident. 
Table 4. The effect of berberine on CVD risk factors and testosterone using a GEE model *

\begin{tabular}{cccc}
\hline Outcomes & Beta & $\mathbf{9 5 \% ~ C I ~}$ & $p$ \\
\hline Total cholesterol (mmol/L) & -0.39 & $-0.62,-0.16$ & 0.001 \\
LDL-cholesterol (mmol/L) & -0.23 & $-0.43,-0.02$ & 0.03 \\
Triglycerides (mmol/L) & -0.31 & $-0.67,0.06$ & 0.10 \\
HDL-cholesterol (mmol/L) & -0.03 & $-0.09,0.02$ & 0.26 \\
SBP (mmHg) & -0.91 & $-4.75,2.93$ & 0.64 \\
DBP (mmHg) & -0.31 & $-3.42,2.80$ & 0.84 \\
BMI & -0.39 & $-0.99,0.21$ & 0.20 \\
WHR & -0.006 & $-0.02,0.01$ & 0.36 \\
Thromboxane A2 (pg/mL) & 8.46 & $-23.0,39.9$ & 0.60 \\
Testosterone (nmol/L) & 1.31 & $0.30,2.33$ & 0.01 \\
\hline
\end{tabular}

* GEE model incorporates changes at 8 and 12 weeks. A GEE model with an exchangeable correlation structure was used.

\section{Discussion}

Our findings extend the current evidence by assessing the effect of berberine in men only, including the effect on testosterone. This RCT in men suggests that berberine affects CVD risk factors by lowering total cholesterol, as well as possibly lowering LDL-c and increasing testosterone.

Our findings are consistent with previous studies showing a beneficial effect of berberine on total cholesterol and possibly LDL-c [5,6,24]. The reduction in HDL-c might have occurred by chance at 12 weeks after treatment because it was not evident when using information at both 8 and 12 weeks, which needs replication. We found a null effect of berberine on thromboxane A2, the effect of which has not been examined previously. Differences in triglycerides, blood pressure and adiposity between the groups were not statistically significant, which is less consistent with some systematic reviews and metaanalyses of RCTs $[8,24,25]$, although the direction of effects were consistent. Moreover, high heterogeneity in the RCTs included in previous meta-analyses, with $\mathrm{I}^{2}$ up to over $90 \%$ [6,24], make their results inconclusive and difficult to interpret. For example, the included trials have varying dosages (from 0.9 to $1.5 \mathrm{~g}$ daily), intervention periods (from 1 month to 2 years) and quality, and few studies were publicly registered [6]. A previous systematic review and meta-analysis also showed that berberine did not lower BMI, but lowered WHR in women [26]. It is also possible that our study was conducted in men without established coronary heart disease or diabetes, whilst berberine may have more obvious effects on CVD risk factors in people with CVD and/or diabetes. As such, it would be worthwhile to replicate an RCT using a larger sample size and assess a wider range of lipids, particularly apolipoprotein B (apoB), which is increasingly thought to be the key lipid relevant to higher risk of CVD [36,37].

To our knowledge, our study has for the first time examined the effect of berberine on testosterone in men, whilst previous RCTs of berberine on sex hormones generally focused on women with polycystic ovary syndrome (PCOS) [23,38]. Supplementation with berberine ( $1500 \mathrm{mg} /$ day for 3 months) lowered testosterone in women with PCOS in two similar sized trials (50 women in each group in one trial [23], and 33 versus 36 women in another trial [38]). In contrast, our study suggests that berberine has different effects on testosterone in men than those found in women. However, the previous trials in women were conducted in women with PCOS [23,38], who tend to have higher testosterone, and effects might be different in women with normal endocrine parameters. As such, to assess any sex difference in the endocrine effects of berberine, an RCT in women without PCOS is needed. Similar sex-specific effects on testosterone have also been suggested for metformin [39], the first-line treatment for type 2 diabetes, which like berberine targets AMPK. Given the similarity and the beneficial effect of testosterone on glucose metabolism [40,41], further examination of the effects of berberine on glucose and endocrine factors, including factors relevant to testosterone, such as sex hormone binding globulin, might also be worthwhile. Considering that sex differences in response to drugs are increasingly 
receiving attention [42], it would be worthwhile to conduct another trial in women in the same setting for comparison, to identify and clarify differential effects of berberine in men and women.

Our study has several strengths. First, our study followed a pre-specified protocol, which avoids selective reporting. Second, our study examined the effect of berberine on testosterone and thromboxane A2 in men for the first time, which may also serve as a reference for future studies on sex-specific effects of berberine. Nevertheless, limitations of the study exist. First, we recruited the participants from the University of Hong Kong and Queen Mary Hospital to facilitate recruitment, and explained to potential recruits the purpose of the study, which might affect participation. However, the randomization removes confounding. The outcomes are also objective measures from a blood test which are unaffected by these factors. Second, the sample size of this study was relatively small. The sample size was estimated based on previous studies [32,43]. Power might be insufficient if the effect size is lower than previously reported, given the heterogeneity in different studies [6]. We also used the GEE model to make the best use of the data. Third, testosterone varies by time of day, however, we collected all the samples in the morning. Fourth, loss to follow-up lowers the sample size and thus lowers the precision in the estimates. However, the directions of estimates are unchanged. Fifth, thromboxane A2 has high variability, so we cannot exclude the possibility that the null effect is due to a lack of power. Sixth, findings in Chinese might not apply to other populations, such as Europeans of different ethnicity. However, causal effects are expected to be consistent across settings, although their relevance might vary by setting [44]. As such, the directions of effects are not expected to be different by population.

Our findings, together with previous evidence, suggest that berberine may lower cholesterol, with good safety. In comparison with previous evidence in women $[23,38]$, our study also indicates that berberine might have sex-specific effects on sex hormones. Exploring other underlying pathways and assessing the sex disparity would be worthwhile, with direct relevance to drug repositioning and healthcare.

\section{Conclusions}

Our findings extend the current evidence by assessing the effect of berberine in men only. Our study showed that berberine lowers total cholesterol and possibly LDL-c, with good safety. Our study also adds to the research by assessing the effect of berberine on testosterone and thromboxane $\mathrm{A} 2$ in men. Berberine did not lower testosterone in men, but instead possibly increased testosterone, in contrast to berberine reducing testosterone in women. Explicating mechanisms underlying any differences by sex and further exploring other pathways, including a wide range of lipids, glucose metabolism and endocrine factors, would be worthwhile.

Supplementary Materials: The following are available online at https:/ /www.mdpi.com/article/10 $.3390 /$ nu13082550/s1, Supplemental Methods. Table S1: Safety profile of berberine in this trial and most recent systematic review and meta-analysis of clinical trials.

Author Contributions: Conceptualization, J.V.Z.; Data curation, J.V.Z., W.-F.Y. and Y.-H.C.; Formal analysis, J.V.Z. and C.M.S.; Funding acquisition, J.V.Z., D.V., J.Y.Y.L., D.K.M.I. and W.-K.H.; Investigation, J.V.Z., Y.-H.C., D.V., J.Y.Y.L., D.K.M.I., J.Z., W.-K.H., H.-F.T. and C.M.S.; Methodology, D.V., J.Y.Y.L., D.K.M.I. and C.M.S.; Project administration, J.V.Z., W.-F.Y., Y.-H.C., J.Z. and H.-F.T.; Supervision, J.V.Z.; Writing—original draft, J.V.Z.; Writing—review \& editing, W.-F.Y., Y.-H.C., D.V., J.Y.Y.L., D.K.M.I., J.Z., W.-K.H., H.-F.T. and C.M.S. All authors have read and agreed to the published version of the manuscript.

Funding: This study was supported by the Health and Medical Research Fund, Food and Health Bureau, Hong Kong SAR Government (\#15162621). 
Institutional Review Board Statement: The study was conducted according to the guidelines of the Declaration of Helsinki and approved by Institutional Review Board of the University of Hong Kong/Hospital Authority Hong Kong West Cluster (UW18-037, date of approval 7 February 2018). The trial would have been discontinued immediately after receiving notification of any clinical serious adverse event.

Informed Consent Statement: All participants were given full information about the trial, informed that participation was voluntary and that they could decline further participation at any time without penalty, and signed a consent form before participation, including consent for use of left-over samples for future research.

Data Availability Statement: The datasets used and/or analyzed during the current study are available from the corresponding author upon reasonable request.

Conflicts of Interest: The authors declare no conflict of interest.

\section{References}

1. Mauvais-Jarvis, F.; Merz, N.B.; Barnes, P.J.; Brinton, R.D.; Carrero, J.J.; De Meo, D.L.; De Vries, G.J.; Epperson, C.N.; Govindan, R.; Klein, S.L.; et al. Sex and gender: Modifiers of health, disease, and medicine. Lancet 2020, 396, 565-582. [CrossRef]

2. Nikiforov, S.V.; Mamaev, V.B. The development of sex differences in cardiovascular disease mortality: A historical perspective. Am. J. Public Health 1998, 88, 1348-1353. [CrossRef] [PubMed]

3. Jackson, N.; Atar, D.; Borentain, M.; Breithardt, G.; van Eickels, M.; Endres, M.; Fraass, U.; Friede, T.; Hannachi, H.; Janmohamed, S.; et al. Improving clinical trials for cardiovascular diseases: A position paper from the Cardiovascular Round Table of the European Society of Cardiology. Eur. Heart J. 2016, 37, 747-754. [CrossRef]

4. Imanshahidi, M.; Hosseinzadeh, H. Pharmacological and therapeutic effects of Berberis vulgaris and its active constituent, berberine. Phytother. Res. 2008, 22, 999-1012. [CrossRef] [PubMed]

5. Kumar, A.; Chopra, K.E.; Mukherjee, M.; Pottabathini, R.; Dhull, D.K. Current knowledge and pharmacological profile of berberine: An update. Eur. J. Pharmacol. 2015, 761, 288-297. [CrossRef] [PubMed]

6. Zhang, L.S.; Zhang, J.H.; Feng, R.; Jin, X.Y.; Yang, F.W.; Ji, Z.C.; Zhao, M.Y.; Zhang, M.Y.; Zhang, B.L.; Li, X.M. Efficacy and Safety of Berberine Alone or Combined with Statins for the Treatment of Hyperlipidemia: A Systematic Review and Meta-Analysis of Randomized Controlled Clinical Trials. Am. J. Chin. Med. 2019, 47, 751-767. [CrossRef]

7. Derosa, G.; D'Angelo, A.; Bonaventura, A.; Bianchi, L.; Romano, D.; Maffioli, P. Effects of berberine on lipid profile in subjects with low cardiovascular risk. Expert Opin. Biol. Ther. 2013, 13, 475-482. [CrossRef]

8. Lan, J.; Zhao, Y.; Dong, F.; Yan, Z.; Zheng, W.; Fan, J.; Sun, G. Meta-analysis of the effect and safety of berberine in the treatment of type 2 diabetes mellitus, hyperlipemia and hypertension. J. Ethnopharmacol. 2015, 161, 69-81. [CrossRef]

9. Derosa, G.; Maffioli, P.; Cicero, A.F. Berberine on metabolic and cardiovascular risk factors: An analysis from preclinical evidences to clinical trials. Expert Opin. Biol. Ther. 2012, 12, 1113-1124. [CrossRef] [PubMed]

10. Chang, W.; Li, K.; Guan, F.; Yao, F.; Yu, Y.; Zhang, M.; Hatch, G.M.; Chen, L. Berberine Pretreatment Confers Cardioprotection Against Ischemia-Reperfusion Injury in a Rat Model of Type 2 Diabetes. J. Cardiovasc. Pharmacol. Ther. 2016, $21,486-494$. [CrossRef]

11. Richter, E.A.; Ruderman, N.B. AMPK and the biochemistry of exercise: Implications for human health and disease. Biochem. J. 2009, 418, 261-275. [CrossRef] [PubMed]

12. Skarydova, L.; Hofman, J.; Chlebek, J.; Havrankova, J.; Kosanova, K.; Skarka, A.; Hostalkova, A.; Plucha, T.; Cahlikova, L.; Wsol, V. Isoquinoline alkaloids as a novel type of AKR1C3 inhibitors. J. Steroid Biochem. Mol. Biol. 2014, 143, 250-258. [CrossRef] [PubMed]

13. Petitti, D. Commentary: Hormone replacement therapy and coronary heart disease: Four lessons. Int. J. Epidemiol. 2004, 33, 461-463. [CrossRef]

14. Luo, S.; Yeung, S.L.A.; Zhao, J.V.; Burgess, S.; Schooling, C.M. Association of genetically predicted testosterone with thromboembolism, heart failure, and myocardial infarction: Mendelian randomisation study in UK Biobank. BMJ 2019, 364, 1476. [CrossRef] [PubMed]

15. Lemaitre, J.F.; Berger, V.; Bonenfant, C.; Douhard, M.; Gamelon, M.; Plard, F.; Gaillard, J.M. Early-late life trade-offs and the evolution of ageing in the wild. Proc. R. Soc. 2015, 282, 20150209. [CrossRef]

16. Schooling, C.M. Could androgens be relevant to partly explain why men have lower life expectancy than women? J. Epidemiol. Community Health 2016, 70, 324-328. [CrossRef]

17. Zhao, J.; Jiang, C.; Lam, T.H.; Liu, B.; Cheng, K.K.; Xu, L.; Long, M.J.; Zhang, W.; Leung, G.M.; Schooling, C.M. Genetically predicted testosterone and electrocardiographic QT interval duration in Chinese: A Mendelian randomization analysis in the Guangzhou Biobank Cohort Study. Int. J. Epidemiol. 2015, 44, 613-620. [CrossRef]

18. Zhao, J.; Jiang, C.; Lam, T.H.; Liu, B.; Cheng, K.K.; Xu, L.; Yeung, S.L.A.; Zhang, W.; Leung, G.M.; Schooling, C.M. Genetically predicted testosterone and cardiovascular risk factors in men: A Mendelian randomization analysis in the Guangzhou Biobank Cohort Study. Int. J. Epidemiol. 2014, 43, 140-148. [CrossRef] 
19. Fernandez-Balsells, M.M.; Murad, M.H.; Lane, M.; Lampropulos, J.F.; Albuquerque, F.; Mullan, R.J.; Agrwal, N.; Elamin, M.B.; Gallegos-Orozco, J.F.; Wang, A.T.; et al. Clinical review 1: Adverse effects of testosterone therapy in adult men: A systematic review and meta-analysis. J. Clin. Endocrinol. Metab. 2010, 95, 2560-2575. [CrossRef] [PubMed]

20. Xu, L.; Schooling, C.M. Differential risks in men and women for first and recurrent venous thrombosis: The role of genes and environment: Comment. J. Thromb. Haemost. 2015, 13, 884-886. [CrossRef]

21. Ajayi, A.A.; Mathur, R.; Halushka, P.V. Testosterone increases human platelet thromboxane A2 receptor density and aggregation responses. Circulation 1995, 91, 2742-2747. [CrossRef]

22. Ajayi, A.A.; Halushka, P.V. Castration reduces platelet thromboxane A2 receptor density and aggregability. QJM 2005, 98, 349-356. [CrossRef]

23. An, Y.; Sun, Z.; Zhang, Y.; Liu, B.; Guan, Y.; Lu, M. The use of berberine for women with polycystic ovary syndrome undergoing IVF treatment. Clin. Endocrinol. 2014, 80, 425-431. [CrossRef] [PubMed]

24. Ju, J.Q.; Li, J.E.; Lin, Q.; Xu, H. Efficacy and safety of berberine for dyslipidaemias: A systematic review and meta-analysis of randomized clinical trials. Phytomedicine 2018, 50, 25-34. [CrossRef]

25. Xiong, P.; Niu, L.; Talaei, S.; Kord-Varkaneh, H.; Clark, C.C.T.; Gaman, M.A.; Rahmani, J.; Dorosti, M.; Mousavi, S.M.; Zarezadeh, M.; et al. The effect of berberine supplementation on obesity indices: A dose- response meta-analysis and systematic review of randomized controlled trials. Complement. Ther. Clin. Pract. 2020, 39, 101113. [CrossRef]

26. Mirzaee, F.; Razmjouei, P.; Shahrahmani, H.; Vafisani, F.; Najafi, M.N.; Ghazanfarpour, M. The effect and safety of Berberine on polycystic ovary syndrome: A systematic review. J. Obstet. Gynaecol. 2020, 41, 684-689. [CrossRef] [PubMed]

27. Yu, M.; Jin, X.; Liang, C.; Bu, F.; Pan, D.; He, Q.; Ming, Y.; Little, P.; Du, H.; Liang, S.; et al. Berberine for diarrhea in children and adults: A systematic review and meta-analysis. Ther. Adv. Gastroenterol. 2020, 13, 1756284820961299. [CrossRef]

28. Moran, A.E.; Forouzanfar, M.H.; Roth, G.A.; Mensah, G.A.; Ezzati, M.; Flaxman, A.; Murray, C.J.; Naghavi, M. The global burden of ischemic heart disease in 1990 and 2010: The Global Burden of Disease 2010 study. Circulation 2014, 129, 1493-1501. [CrossRef] [PubMed]

29. Wittes, J. Sample size calculations for randomized controlled trials. Epidemiol. Rev. 2002, 24, 39-53. [CrossRef] [PubMed]

30. Zhong, B. How to calculate sample size in randomized controlled trial? J. Thorac. Dis. 2009, 1, 51-54.

31. Expert Panel on Detection, Evaluation and Treatment of High Blood Cholesterol in Adults. Executive Summary of the Third Report of the National Cholesterol Education Program (NCEP) Expert Panel on Detection, Evaluation, and Treatment of High Blood Cholesterol in Adults (Adult Treatment Panel III). JAMA 2001, 285, 2486-2497. [CrossRef] [PubMed]

32. Zhang, Y.; Li, X.; Zou, D.; Liu, W.; Yang, J.; Zhu, N.; Huo, L.; Wang, M.; Hong, J.; Wu, P.; et al. Treatment of type 2 diabetes and dyslipidemia with the natural plant alkaloid berberine. J. Clin. Endocrinol. Metab. 2008, 93, 2559-2565. [CrossRef]

33. Cochrane Handbook. Available online: https://handbook-5-1.cochrane.org/chapter_16/16_2_1_introduction.htm (accessed on 6 July 2021).

34. Albert, P.S. Longitudinal data analysis (repeated measures) in clinical trials. Stat. Med. 1999, 18, 1707-1732. [CrossRef]

35. Hanley, J.A.; Negassa, A.; Edwardes, M.D.; Forrester, J.E. Statistical analysis of correlated data using generalized estimating equations: An orientation. Am. J. Epidemiol. 2003, 157, 364-375. [CrossRef]

36. Richardson, T.G.; Sanderson, E.; Palmer, T.M.; Ala-Korpela, M.; Ference, B.A.; Smith, G.D.; Holmes, M.V. Evaluating the relationship between circulating lipoprotein lipids and apolipoproteins with risk of coronary heart disease: A multivariable Mendelian randomisation analysis. PLoS Med. 2020, 17, e1003062. [CrossRef] [PubMed]

37. Glavinovic, T.; Sniderman, A.D. Apolipoprotein B: The Rosetta Stone of lipidology. Curr. Opin. Endocrinol. Diabetes Obes. 2021, 28, 90-96. [CrossRef]

38. Wei, W.; Zhao, H.; Wang, A.; Sui, M.; Liang, K.; Deng, H.; Ma, Y.; Zhang, Y.; Zhang, H.; Guan, Y. A clinical study on the short-term effect of berberine in comparison to metformin on the metabolic characteristics of women with polycystic ovary syndrome. Eur. J. Endocrinol. 2012, 166, 99-105. [CrossRef]

39. Luo, S. An Investigation of Metformin's Etiological Role in Major Chronic Diseases Using Mendelian Randomization; HKU: Hong Kong, China, 2020.

40. Ruth, K.S.; Day, F.R.; Tyrrell, J.; Thompson, D.J.; Wood, A.R.; Mahajan, A.; Beaumont, R.N.; Wittemans, L.; Martin, S.; Busch, A.S.; et al. Using human genetics to understand the disease impacts of testosterone in men and women. Nat. Med. 2020, 26, 252-258. [CrossRef] [PubMed]

41. Perez-Rubio, K.G.; Gonzalez-Ortiz, M.; Martinez-Abundis, E.; Robles-Cervantes, J.A.; Espinel-Bermudez, M.C. Effect of berberine administration on metabolic syndrome, insulin sensitivity, and insulin secretion. Metab. Syndr. Relat. Disord. 2013, 11, 366-369. [CrossRef] [PubMed]

42. Bartz, D.; Chitnis, T.; Kaiser, U.B.; Rich-Edwards, J.W.; Rexrode, K.M.; Pennell, P.B.; Goldstein, J.M.; O’Neal, M.A.; LeBoff, M.; Behn, M.; et al. Clinical Advances in Sex- and Gender-Informed Medicine to Improve the Health of All: A Review. JAMA Intern. Med. 2020, 180, 574-583. [CrossRef]

43. Gu, Y.; Zhang, Y.; Shi, X.; Li, X.; Hong, J.; Chen, J.; Gu, W.; Lu, X.; Xu, G.; Ning, G. Effect of traditional Chinese medicine berberine on type 2 diabetes based on comprehensive metabonomics. Talanta 2010, 81, 766-772. [CrossRef] [PubMed]

44. Lopez, P.M.; Subramanian, S.V.; Schooling, C.M. Effect measure modification conceptualized using selection diagrams as mediation by mechanisms of varying population-level relevance. J. Clin. Epidemiol. 2019, 113, 123-128. [CrossRef] [PubMed] 